\title{
PREDICTION OF FRACTURE OF EGGSHELL USING OPERATIONAL MODAL ANALYSIS
}

\author{
Amer Essa A.H. \\ Department of Agriculture Engineering, \\ Faculty of Agricultural \\ Minoufiya Universit \\ Shibin El-Kom, EGYPT \\ aymanamer64@yahoo.com
}

\author{
Gomaa. F. R. \\ Department of Production Eng. \& Mech. \\ Design, Faculty of Engineering, \\ Minoufiya University, \\ Shibin El-Kom, EGYPT
}

FawkiaGomaa@yahoo.com

\begin{abstract}
.
Presence of crack in eggshell are suspect able due to higher speed in commercial egg grading machines, so non-destructive quality assessment of bioproducts using vibration analysis, the resonant frequency and the damping of the vibration are the main parameters for the nondestructive quality assessment. The focus of this research is to investigate the capability of the operational modal analysis as a nondestructive tool, to characterize and to quantify the fracture behavior of eggshell. This is achieved by studying the response of modal testing to the variation in strength as the main factor affecting fracture. This help in correlating modal parameters to fracture behavior. Two different methods are achieved1- traditional modal analysis using transfer function between actuator and sensor and 2- operational modal analysis using transmittance function between pairs of sensors, input excitation was provided through a piezoelectric force transducer bonded to the center of the cup used for egg installation in order to extract the corresponding modal parameters and damping ratio. The test for strength was performed on eggs to correlated modal parameter to behavior of fracture. This enables the evaluation of the ability of modal testing to predict fracture using an empirical formula. The damage index based on change in transmittance function is very sensitive to change in crack length. Structural information obtained about a biomaterial at different length scales is important in relating the structure to its functional properties. This knowledge and the principles behind the formation of biomaterials could be used in the attempt of bioengineering new systems.
\end{abstract}

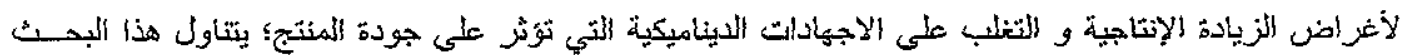

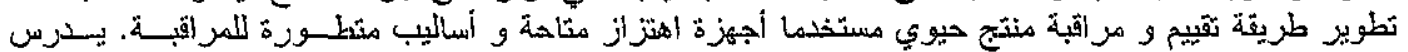

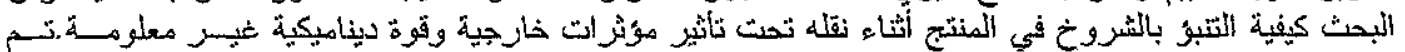

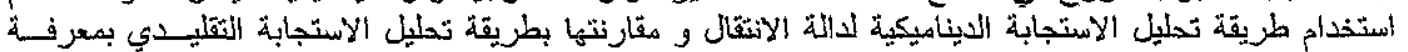

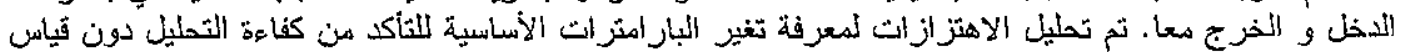

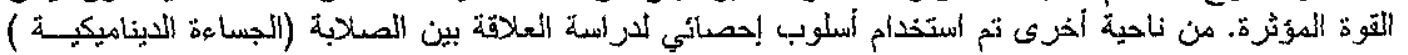

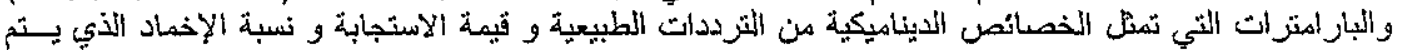

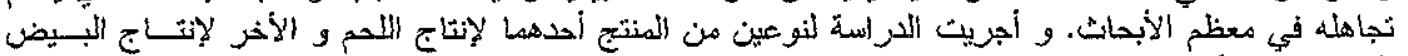

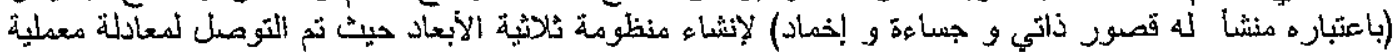

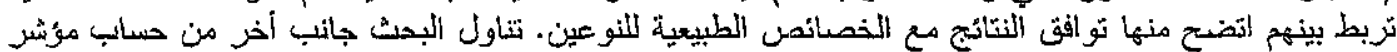

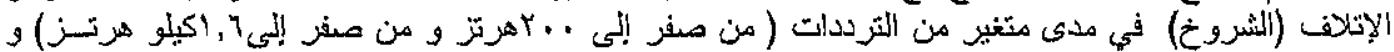

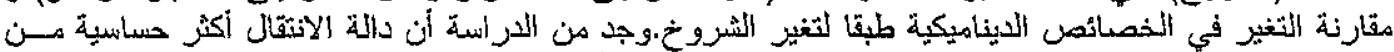

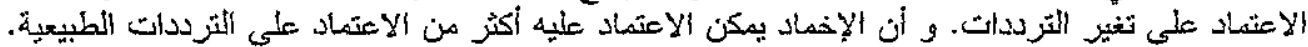

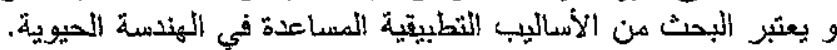

Keywords: Modal testing, Damage detection, operational Modal analysis, Structural health monitoring, operating deflection shape.

\section{INTRODUCTION.}

In commercial egg production, cracking of eggshells is a common occurrence resulting in downgrading of eggs and substantial economic losses. Also cracked eggs are more vulnerable to Salmonella and other bacterial infections leading to health hazards. Therefore, detection and removal of cracked eggs continue to be very important for quality assurance 
in egg industry. Candling is a reliable and most often used technique for egg quality assessment. However, egg candling is an immensely difficult task and requires a combination of great skill, practice and concentration by the human operators, especially when linking it with high speed grading machines. As a result, attempts have been made to replace the human operators with the so called machine vision systems to detect cracks and other defects on egg surface [1-3]. It has been shown that several problems associated with the misclassified images may affect the overall accuracy of such systems considerably [4]. Recently it has been reported that acoustic impulse resulting from a light mechanical impact could be used for online inspection of eggshell cracks non-destructively in real time [5-6]. [5] Developed classification criteria for detecting surface cracks in shell eggs based on the frequency spectrum of acoustic impulse using multiple regression and multivariate discriminate ánalysis. The errors associated with incorrect identification of cracked and intact eggs were found 4 and $6 \%$, respectively. In another approach, [6] used Pearson correlation coefficients between the frequency spectra of acoustic response to classify eggs. They showed about $90 \%$ accuracy for cracked egg detection with a false reject of less than $0.5 \%$.

Artificial neural networks (ANNs) have been widely applied to classification problems in many fields. Several successful implementations of ANN classifiers reveal their capability to extract trends and patterns from the large data sets [7-10]. They offer significant advantages when dealing with noisy or obscure patterns over the statistical pattern classifiers [10].

Due to higher speeds in commercial egg grading machines (wbich grade up to 120000 eggs $/ \mathrm{h}$ ), an automated quality sorting principle is of interest to assure a consistent egg quality. One of the main physical quality parameters for consumption eggs is the presence of a crack in the eggshell. Very recent research shows that it is possible to detect cracks in eggshells on-line using vibration analysis $[6,11$, $12 \& 13]$. For this purpose, the egg is hit four times around its equator and the similarity (correlation) between the four measurements is used as a sorting criterion. In this way, up to $90 \%$ of the cracks can be removed while the number of false rejects (the percentage of intact eggs that are classified as broken) remains well below $0.5 \%$ [6]. Because of complexity of eggs structure and transporting condition, no clear guideline and methodology for experimental analysis of eggs dynamic characteristics has emerged especially damping on line with eggs shell strength to have the proper estimation of eggshell life. To avoid sudden or unexpected fracture of eggshell is presented with correlating to strength. Two methods for estimating modal damping to verify the accuracy of the estimated modal damping ratio [14].

The research in this paper focuses on the question of whether it is possible to use vibration measurements to assess eggshell strength, as another important quality parameter, in an on-line way. This is a further step towards an integrated, on-line egg quality assessment.

In the literature, different techniques can be found for determining eggshell strength. In general, they can be split up into direct methods and indirect methods [15]. Indirect methods measure a parameter that is related to the eggshell strength. The correlation between the different methods is moderate, and the choice of which method to choose often depends on the application. Most methods are destructive.

Measuring the eggshell thickness is one of the frequently used indirect methods to have an indication of the eggshell strength. Using a micrometer, it is possible to determine the thickness up to $0.02 \mathrm{~mm}$. Another indirect measure for the strength of the egg is provided by the calculation of the pexcentage eggshell. [16] Show that $80 \%$ of the percentage breakage of a batch of consumption eggs can be explained by this percentage. A third widely used indirect method makes use of the quasi-static compression of the eggs between two parallel plates. By measuring the force deformation curve, it is possible to determine the static stiffness of the egg. In the present study, this method is used as a reference.

Different direct methods are described in the literature. The most widely used is the compression fraction force measured during quasi-static compression [16, 17]. Other methods include puncture tests and impact tests. All direct methods are destructive.

From the literature, it appears that their behavior has been simulated as a mass-spring system from which the stiffness of the product is the factor describing its quality. The stiffness of the product is hence a function of both the mass of the object and its resonant frequency given by [12] with the dynamic stiffness, the mass of the egg and the resonant frequency. This is clearly an invariable model, linking only one vibration parameter (the dynamic stiffness) with a reference quality parameter. The dynamic stiffness to estimate the static stiffness is used of the eggshell. This invariable model is not applicable as such for eggshell strength assessment because of the moderate correlation between the $k d y n$ and kstat [18]. The current study focuses on the 
expansion of the invariable model to obtain more accurate estimates of the eggshell strength. Additional and improved information will be provided by:

(1) A very accurate estimation of the resonant frequency (note that it is quadratically related to the dynamic stiffness and hence plays a crucial role).

(2) Expanding the model by incorporating the damping of the vibration, which was ignored in all research found in the literature; including the mode shape, and put an empirical formula to correlate between modal parameters (natural frequency, damping ratio and magnitude of frequency response function) and strength.Therefore, the objective of this study was to develop a method for detecting eggshell cracks based on transmittance function of frequency response of eggs on line.

\section{BACKGROUND FOR DAMAGE DETECTION.}

Many methods of detecting damage have been proposed. One of the approaches that have received considerable attention in the technical literature is vibration mbased damage detection. The fundamental behind vibration based on damage detection techniques is that changes in the physical properties will alter a system's modal properties such as natural frequencies, modal shapes and damping. The discussion herein focuses on feature selection for damage detection [19] summarizing many features that have been proposed for vibration based-damage detection.

Comprehensive literature reviews of subject structural health monitoring can be found $[20-22]$. [23] Using chaotic input signature and a state-space method for damage detection. A novel feature cailed the local attractor variance ratio was developed using chaos theory. They showed how a properly tuned chaotic excitation could be used to robustly detect structural changes. Techniques based on neural networks require a model to train the system to detect damage [ 39]. [25] Investigated the damage detection of composite ship hulls using neural networks. They developed a finite element model for a stiffened plate to stimulate dynamic response of the structure with and without damage. Very small damage in composite materials, such as cracks, were successfully found using wavelet analysis [24]. [27] Used a fuzzy logic system to locate damage on helicopter rotor blades. A fuzzy logic system can be expressed as a linear combination of fuzzy basis function and is a universal function approximates.[26] Presented a review of various investigations on the effects of structural damage on natural frequencies. Many damage location methods use change in resonant frequencies because frequency measurement can quickly conducted and are often reliable, however, changes in ambient condition can cause significant frequency change in composite materials, and findings suggest that detection of damage using frequency measurements might be unreliable when the damage is located at regions of low stress. [28] Used transfer functions to determine the extent of joint loosening in automobile vehicle frames with high mileage. The method was successful but did not give specifics for frequency range investigated and what type of (FRFs) were utilized.

The successful transmittance function testing for wind turbine blade damage analysis was presented by [29] and by [30]. And [37] used three different monitoring techniques at low frequency modal analysis and for high frequency transfer functions between the actuator and sensors and transmittance function between two pairs of sensors and experiments demonstrate that the transmittance function is very sensitive to change bolt load. To confirm the characteristic of transmittance function technique. This paper is focused to detect fracture in egg shell. For non standing signal due to variable force level which was not measured, and compared to traditional modal analysis.

\section{OPERATIONAL MODAL ANALYSIS USING TRANSMITTANCE FUNCTION.}

Transmittance testing procedures are similar to the procedure using transfer function $[36,37]$. For the transmittance test the response in frequency domain of two sensors is compared with each other. In contrast to this test the response of the sensor is compared to excitation signals. Thus, for transmittance testing, sensor A was connected to input channel $A$ and sensor $B$ was connected to reference channel $B$. The transmittance function between two response points, a \& b was calculated using. $T_{a b}(f)=\frac{G_{a b}(f)}{G_{b b}(f)}$

where

$\mathrm{G}_{\mathrm{bb}}$ : is Auto spectral density function.

$\mathrm{G}_{\mathrm{ab}}$ : cross spectral density function one side auto spectral density function and cross spectral can be computed from real data as

$$
\begin{aligned}
& G_{b b}(f)=\frac{2}{\left(n_{d} \Delta T\right)} \sum_{i=1}^{n_{t}} B(f, T) B^{*}(f, T) \ldots . .(f>0) \\
& G_{a b}(f)=\frac{2}{\left(n_{d} \Delta T\right.} \sum_{i=1}^{n_{s}} A(f, T) B^{*}(f, T) \ldots . .(f>0)
\end{aligned}
$$


The spectral densities are a function of frequency can be averaged across $\left(n_{d}\right)$, where $n_{d}$ : is distinct sub-record of duration $\Delta T, *$ : Complex conjugate. The cross spectral density function is the Fouier transform of the cross correlation function, it represents the frequency domain, characterization of similarity of the magnitude and phase of two signals, there fore it can accurately detect damage over small distance on structure. Further more, measure transmittance data have complete information on the dynamic behavior of the test structure, in terms of vibration modes and damping, at many frequency points. So it is much easier to display ODS.S from set of ODS FRF and observe mode shapes at resonance frequencies. The magnitude of scale factor is calculated by equation (4) [31], here as

Scale factor $(i)=\frac{\cdot \sum_{i=1}^{\text {No.of } A \text { Meatsests }} A R M(i)}{\text { No.of.Meas.setXARM(i) }}$

Where ARM (i) =Average value of the reference response APs for measurements set (i). This scale factor corrects each of ODS FRF magnitude according to average level of all reference response signals and average value can be calculated for any desired range of frequency samples [35].

\section{MATERUALS AND PROCEDURES.}

The eggs $(n=200)$ used in the test originated from two genetically different lines of layers strains as in (table 1). The feed for the birds was a commercial diet. The hens were ( 65 weeks) old at the time of sampling.

\subsection{Experimental procedure.}

An experimental scheme was created to investigate two different health-monitoring methods to show the effect of two methods to detect fracture. One of the aims of this paper is the evaluation of change in fundamental modal properties and correlated modal parameter to strength of eggshell. The experimental performed on two types of egg as the same shape (type A Ross) and type B Lohmann) considerable variation in strength the characteristics of two types are as in Table(1)

The experimental procedure of dynamic test for set of experimental is as follow:

1- Subjecting two types of egg $(A, B)$ to traditional modal hammer test as in Fig. (la, b), and to evaluate modal parameter and mode shape.

2- Subjecting two types of egg (A, B) to operational modal analysis using evaluation of transmittance function with the egg subjected to high frequency range $1.6 \mathrm{KHz}$ as in Fig.(3a ,b), and make comparison as in Table 2.

3- Applying strength test to detect variation of strength related to modal parameter and check sensitivity to modal parameter to variation of strength as in Table 3 to construct an empirical formula.

4- Subjecting the egg to transmittance function to detect damage in eggshell and check the sensitivity of transmittance test to detect damage as in Fig. (8).

\begin{tabular}{|l|c|c|}
\hline $\begin{array}{l}\text { Table (1). Means and standard deviation of measured and } \\
\text { calculated variables for the egg shell characteristics. }\end{array}$ \\
\hline Item & \multicolumn{2}{|c|}{ Mean \pm S.D } \\
\cline { 2 - 3 } & $\begin{array}{c}\text { Lohmann Selccted } \\
\text { Leghom for laying }\end{array}$ & Ross for broiler \\
\hline Egg Shape Index (\%) & $78.247 \pm 4.161$ & $78.885 \pm 4.022$ \\
\hline $\begin{array}{l}\text { Egg Specific } \\
\text { Gravity }\left(g / \mathrm{cm}^{3}\right)\end{array}$ & $1.087 \pm 0.002$ & $1.080 \pm 0.004$ \\
\hline Shell Weight Dried (gm) & $6.341 \pm 0.426$ & $5.274 \pm 0.769$ \\
\hline Egg Volume $\left(\mathrm{cm}{ }^{3}\right)$ & $63.718 \pm 3.324$ & $56.345 \pm 4.374$ \\
\hline Shell percentage $(\%)$ & $9.76 \pm 0.08$ & $8.44 \pm 0.10$ \\
\hline Shell Deformation $(\mu \mathrm{m})$ & $56.3 \pm 13,34$ & $59.2 \pm 10,63$ \\
\hline Breakage Strength $(\mathrm{N})$ & $31.67 \pm 12.59$ & $28.33 \pm 8.302$ \\
\hline Shell Stiffiness $(\mathrm{N} / \mu \mathrm{m})$ & $0.200 \pm 0,04$ & $0.187 \pm 0,03$ \\
\hline Shell density $\left(\mathrm{mg} / \mathrm{cm}^{2}\right)$ & $2750 \pm 0.014$ & $2538 \pm 0.014$ \\
\hline Poisson's ratio & 0.3 & 0.3 \\
\hline Young's modulus $(\mathrm{GPa})$ & $29.79 \pm 0.142$ & $27.16 \pm 0.142$ \\
\hline
\end{tabular}

\subsubsection{Test equipment}

The response of the eggshell sensed by a light piezoelectric accelerometer, weight (2.2 gm), mounting surface flatness, charge sensitivity $(0.318)$ $\mathrm{pc} / \mathrm{ms}^{-2}$, voltage sensitivity $(0.415) \mathrm{mv} / \mathrm{ms}^{-2}$ which was bonded to the opposite direction of impact hammer using a wax for free suspension that represent the inherent properties of egg. Without regard to the external constraint condition at frequency $(0-1.6 \mathrm{KHz})$, both signals from impact hammer and accelerometer were supplied to FFT analyzer as in Fig. ( $1 \mathrm{a}, \mathrm{b}$ ), and estimation FRF with a narrow band of $800 \mathrm{~Hz}$, centered around the fundamental frequency a sample of FRF and coherence function are in Fig. (2) Because of complexity of eggs structure and transporting condition there is no clear guide line and methodology for experimental analysis to be emerged. As mentioned this work focused on two different methods for vibration measurements traditional Modal Analysis (TMA) and transmittance function (T.F). 
Amer Essa A.H. and Gomaa. F. R., "Prediction of Fracture of Eggshell Using Operational Modal Analysis"

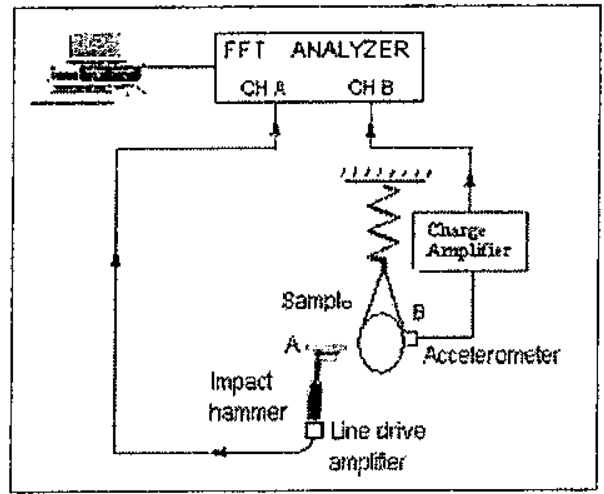

Fig. $(1, a)$. Schematic layout of the system used for (TMA) modal analysis.

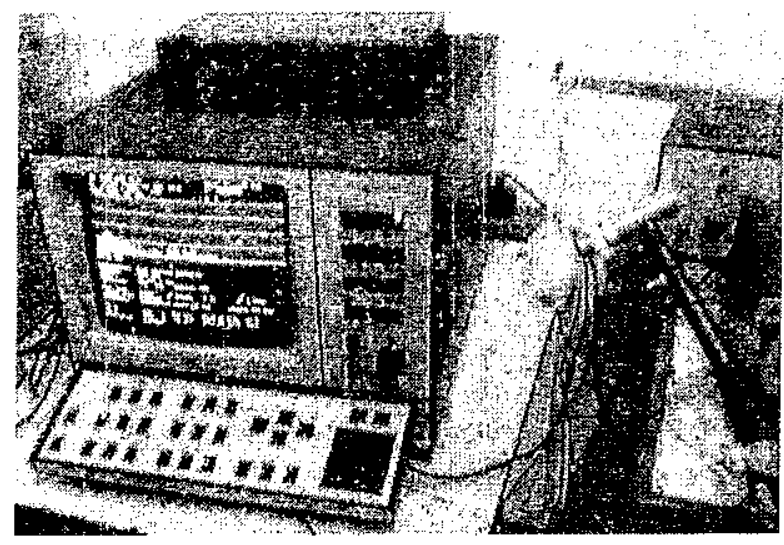

Fig. (1.b). Free suspension for modal analysis.

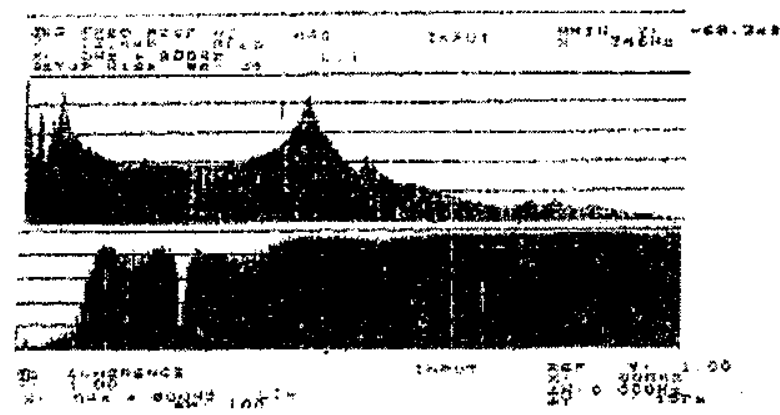

Fig. (2) A sample of FRF and coherence function .

In order to verify the accuracy of the estimated modal damping, the same set of data were presented using operating moving average ODS [31]. Fixed installation using cup and transmittance function were obtained experimentally, as in Fig. ( $3 a, b)$ TThe support of the egg is chosen in such away that they coincide with the nodal points of the first elliptic\}. The system excitation was using exciter control through generator with variable force but did not measure. For transmittance testing sensor $A$ was connected to input channel $A$ and sensor $B$ was connected to reference channel B of FFT analyzer.
Thus the transmittance function $A$ with respect to $B$ was calculated according to equation (1). Transmittance function estimation was made in frequency range from $0 \mathrm{~Hz}$ to $1.6 \mathrm{KHz}$, which was divided into a series of sub range with $200 \mathrm{~Hz}$ band width as in Fig. (4). The identification within the frequency domain is done by using curve fitting, as shown in Table 2 . The very good agreement between the two sets of natural frequency and damping ratios validates the use of either approach for modal analysis of eggshell

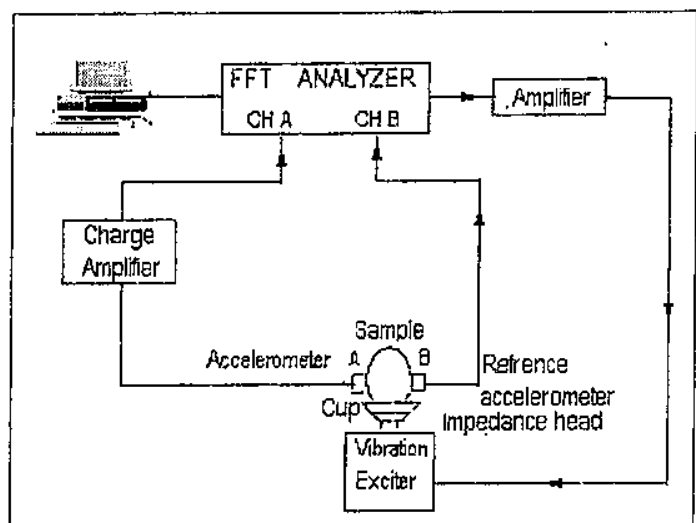

Fig. (3 a,). Schematic layout of the system used for operation modal analysis.

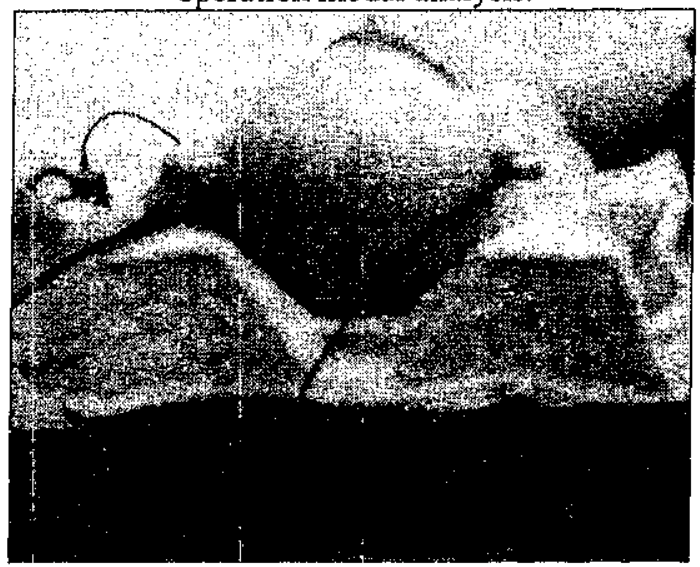

Fig. $(3, b)$. Fixed installation using cup used for operation modal analysis.

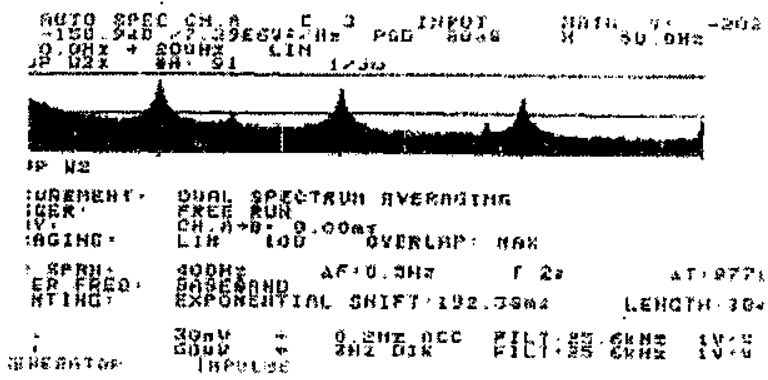

Fig. (4) Auto spectrum for sub range with $200 \mathrm{~Hz}$. Band width. 
Table (2). Comparison of natural frequencies (Hz) and modal damping loss factor $(\eta, \%)$ obtained by two different methods.

\begin{tabular}{|c|c|c|c|c|}
\hline \multirow[t]{2}{*}{ Methods } & \multirow[t]{2}{*}{ Items } & \multicolumn{3}{|c|}{ Mode No. } \\
\hline & & 1 & 2 & 3 \\
\hline \multirow{2}{*}{$\begin{array}{lr}\text { Modal Test } \\
\text { using Impact } \\
\text { Hammer }\end{array}$} & Frequency (Hz) & 346 & 940 & 1600 \\
\hline & $\begin{array}{l}\text { Damping loss } \\
\text { factor }(\eta, \%)\end{array}$ & 0.018 & 0.014 & 0.006 \\
\hline \multirow{2}{*}{$\begin{array}{l}\text { Modal Aralysis } \\
\text { using } \\
\text { transmittance } \\
\text { function }\end{array}$} & Frequency (Hz) & 350.5 & 942 & 1595 \\
\hline & $\begin{array}{l}\text { Damping loss } \\
\text { factor }(\eta, \%)\end{array}$ & 0.015 & 0.012 & 0.005 \\
\hline
\end{tabular}

\section{DETERMINATION OF THE DYNAMIC MODULUS OF ELASTICITY OF THE EGGSEELL AND MODE MEASUREMENTS.}

From measured resonance frequency, the dynamic modulus of elasticity of the eggshell can be calculated by the formula for complete spherical shells and the modes due to extensional deformation alone, i.e. modes independent of the circumferential angle. This is reasonable approximation for thin shell. The modes must be either purely extensional or coupled bending, extensional according to equation $(5)[33,38]$.

$$
\omega_{n i}=\frac{\lambda_{i}}{2 \Pi R}\left[\frac{\mathrm{E}}{\mu\left(1-v^{2}\right)}\right]^{\frac{1}{2}}
$$

Where $\mathbf{i}=0,1,2$,

$\lambda_{i}=$ Nondimensional frequency parameter depending on natural frequency [38].

$$
\lambda_{l}=\left[\frac{2(1+v)}{1+\frac{h^{2}}{12 R^{2}}}\right]^{\frac{1}{2}}
$$

where $\mathrm{E}, \mu, h, R, V$, are modulus of elasticity, density of the shell material, thickness of the shell, radius of the sphere to the mid surface and Poisson ratio respectively .

All vibration modes with the frequency bellow (1.6 $\mathrm{KHz}$ ) were calculated using FEA mat lap tool box for the described circular egg shell as listed in table 1. Three vibration modes were found. The first mode occurs around $(350 \mathrm{~Hz})$ and is the first extensional mode. As mentioned above a slight peak is found in the frequency spectrum of the egg around this frequency. Modal analysis indicates that slight peak corresponds with the first vibration mode Fig. (2). The second mode calculated, around $(550 \mathrm{~Hz})$ is more complex mode, and the nodal point, occurs at the point fixed which explain why no peak is found in frequency spectra around $(550 \mathrm{~Hz})$. The test procedure is thus unable to detect the second vibration mode. The third mode calculated occurs around $(1600 \mathrm{~Hz})$ and is associated with the second coupled bending extensional. Fig. (5) Visualize the pure extensional modes. The position of the eggshell in rest is depicted as in Fig. (3b) during the vibration of the eggshell. The dominant resonant frequency detected in the test procedure occurs around the frequency in Table 2. The mode shape, and elastic modulus of elasticity are calculated according to equations (1-5) which the measurements of the amplitude of the vibration are measured at eight points distributed along the circumference of the eggshell under radial excitation for type (Ross) as in Fig. (5)

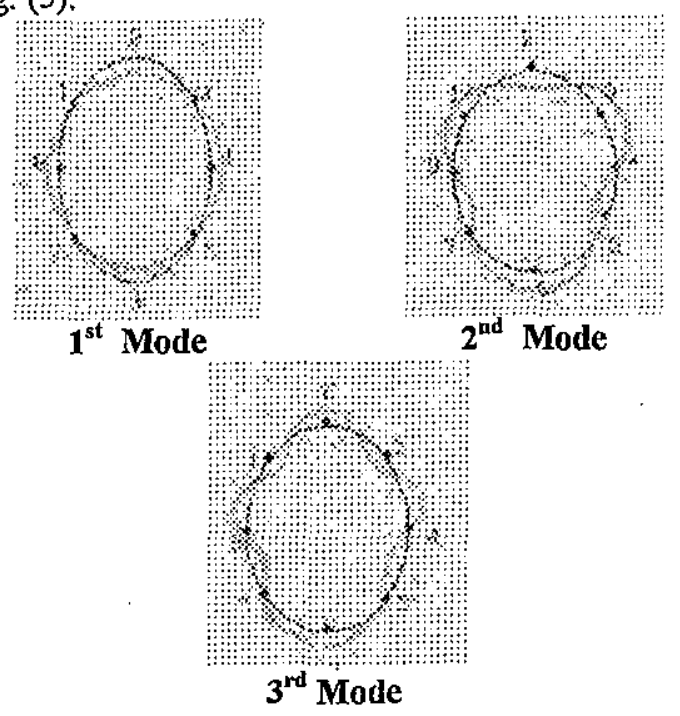

Fig. (5) Mode shape

\section{STRENGTH TEST.}

A total of 24 eggs were tested with a strength test for Lohmann selected Leghorns for laying eggtype chicken breeder and Ross shell eggs for broiler breeder. Specific gravity of the egg was measured by the floatation method using salt solutions ranging in specific gravity from $(1.072$ to 1.090$) \mathrm{g} / \mathrm{cm}^{3}$ with gradients of 0.003 . Shell deformation measurement device was controlled by microprocessor. Shell deformation was measured at the equator of egg. A force change of $0.981 \mathrm{~N}$ (first load) to $9.81 \mathrm{~N}$ (main load) was taken at a resolving power $(1 \mu \mathrm{m})$ and maximum diameter of egg allowance to measure shell deformation was ( $52 \mathrm{~mm}$ ). The force and deformation were recorded throughout the test and used to calculate the static stiffness. A modification of the breakage strength apparatus [34] was used to assess shell breakage strength $P(\mathrm{~N})$ as a nondestructive compression of an egg between two parallel plates. The rate of application of force was controlled precisely. Shell thickness $(\mathrm{mm} / 100)$ was measured with a vice caliper to the nearest $0.01 \mathrm{~mm}$. The average thickness was calculated from three measurements at the equatorial region of the egg 


\section{Amer Essa A.H. and Gomaa. F. R., "Prediction of Fracture of Eggshell Using Operational Modal Analysis"}

(two in the poles and one in the middle part) the measurements were taken after the shell was dried and expressed as $\mathrm{mm}$. xl00. The whole egg mass and shell mass was measured with an electronic weighing balance to an accuracy of $(0.01 \mathrm{~g})$.

\section{DETECTION FRACTURE USING (TRANSMITTANCE FUNCTION).}

In this test, the response in frequency domain of two sensors, moving sensor (A) and reference sensor (B) is compared with each other as depicts in Fig. (3b). Sensor A was connected to input channel A and reference sensor was connected to channel $B$ and the egg is fixed supported as in Fig (3a) for the artificial excitation the exiting force with variable level force which does not measure. In this test, a roving accelerometer was used to measure two degree response at eight points on the egg. Each measurements set consist of APS for once roving response, APS of one reference response and cross power spectrum between roving and reference response pair, the transmittance function estimation were made in frequency range from $(0 \mathrm{~Hz}-1.6 \mathrm{KHz})$ which was divided into a series of sub ranges of 200 $\mathrm{Hz}$ band the variation band width were investigated so to determine the best range to detect crack for this particular egg structural, (0-200) as in Fig. (8). the use of smaller band width allows for high frequency resolution than would be possible damage estimates were taken over entire $(0-1.6 \mathrm{KHz})$ range.

\section{RESULTS AND DISCUSSION.}

\subsection{Strength vs. modal parameter (Prediction of eggshell strength using modal analysis).}

Ross eggshell have lower damping ratio than Lohmann selected Leghorn eggshell. The decreasing of damping ratio with the strength is noticed for two types of eggshell as in Fig (6a).

The natural frequency shows greater response to the eggshell type as in Fig. (6b), this can be explained by the dependency of natural frequency on the modulus of elasticity which varies within the two different types of eggshell. The magnitudes of FRF are sensitive to the type of eggshell. Finally, it can be concluded that $\omega_{\mathrm{n}}$, FRF magnitude are sensitive to type of eggshell Lohmann and Ross to be tested. $\omega_{n}$ is mainly dependent on eggshell type which can be explained by the dependency of natural frequency on eggshell stiffness that is affected by physical composition.

The aim of this set of experiments is to correlate the modal parameters with the results of strength test performed on Lohmann and Ross eggshell treated at conditions explained in table 3 . The modal parameters $\left(\eta, \omega_{n}\right.$, magnitude $\left.F R F\right)$ were plotted against strength as in Fig. $(6 a, b, c)$.The plot of FRF magnitude against the strength shows that the strength increase as the FRF increases as in Fig. (6 c).

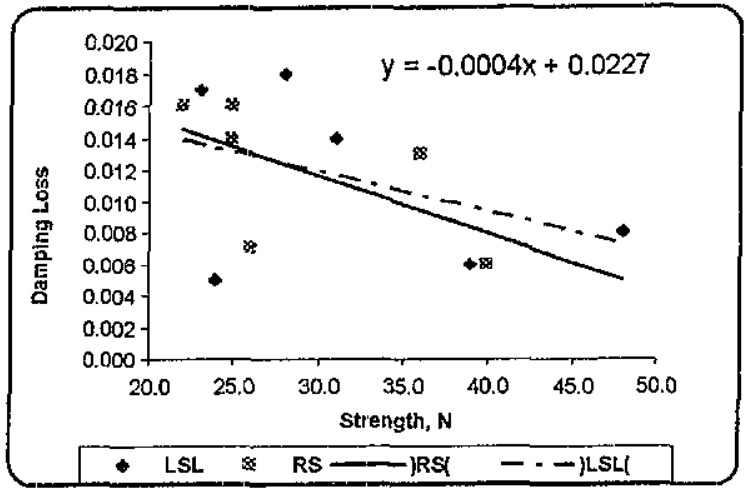

(a)

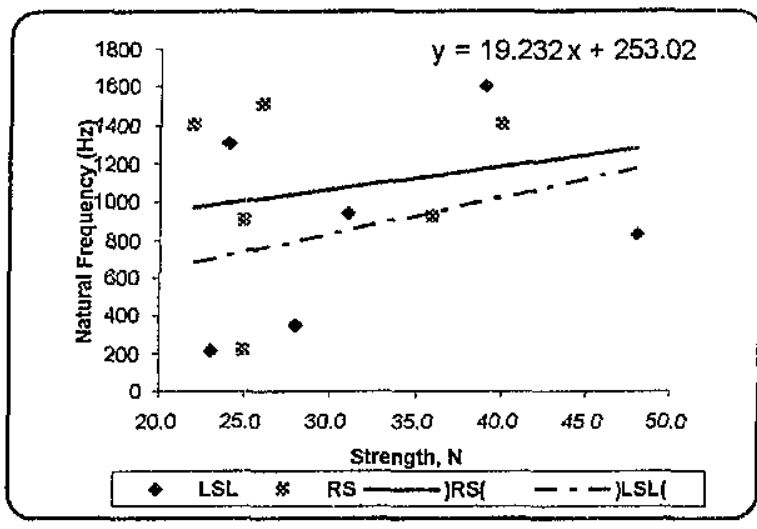

(b)

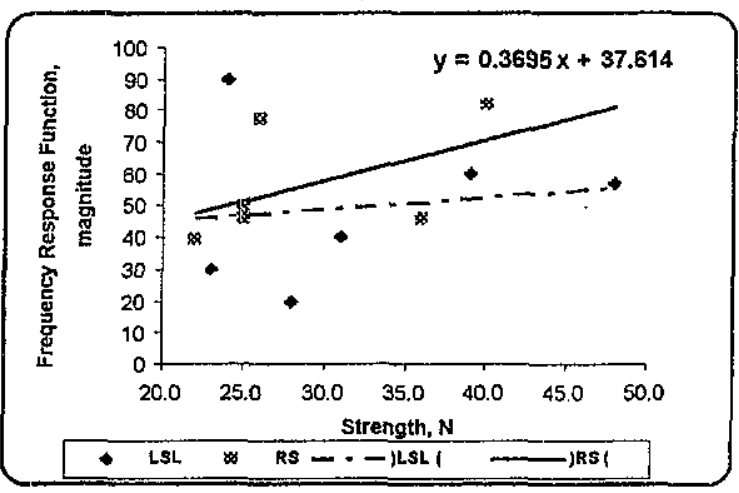

(c)

Confidence level $=98 \%$ to $99.7 \%$

Fig. (6). Strength vs. modal parameter (For two types of egg).

The opposite trends of damping ratio It seams as quasiuniform mass damping. The FRF with strength is explained by the nature between FRF magnitude and damping ratio which an increase in the damping ratio leads to a decrease in magnitude of FRF, Fig. (6b) shows that $\omega_{\mathrm{n}}$ has large variation of strength. This was to be expected since the $\omega_{n}$ is related to 


\section{Amer Essa A.H. and Gomaa. F. R., "Prediction of Fracture of Eggshell Using Operational Modal Analysis"}

dynamic stiffness and mass was almost constant; this relation was also found by [32]. Fig. (6d) shows the response surface of strength as a function of natural frequency $(\omega)$ and FRF. It can be observed from surface plot that FRF increase with increasing of strength and natural frequency that increase dynamic stiffness. This result is in according with the effect of composition of egg on strength that shows an enhancement with increasing of dynamic stiffness.
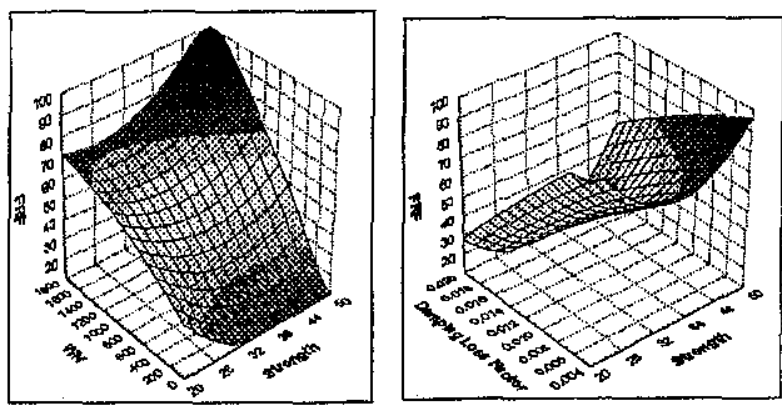

Fig. $(6, d) g$ Response surface of strength as a function of FRF $\omega_{\mathrm{n}}$ and $\eta$.

\subsection{Multi regression Analysis.}

Multi linear regression is applied to establish an empirical formula that correlates the modal Parameter $\left(\eta, \omega_{n}\right.$, and FRF magnitude) which calculated with both low and high resolution estimates with the strength. It aims to estimate the strength of Lohmann and Ross eggshells as a function of its modal parameters.

Step wise procedure SAS [40] was used to select the most relevant parameter T-Test is applied on the input variable in order to determine the most significant parameters that affected the response to avoid the nonsignificant parameter on the proposed model. Table 3 , shows the results. The strength at force equal $(10 N)$ can be correlated to modal parameters ( $\eta, F R F, \omega n)$. The final modal for prediction strength for two types is given by equations $(6,7)$.

The data analysis of this experiment was carried out by using the statistical analysis system (statistical analysis system, 2000). Measured data were analyses by ANOVA. Least significance Difference test was used to determine between means. Significance was assumed at $(\mathrm{p} \leq 0.05)$

Linear, non-linear and stepwise regressions were performed using program GLM (SAS.2000) variable with distribution were transformed prior to performing the statistical analysis.

$$
\begin{array}{r}
\text { Strength }=625 \eta-0.0008 \omega n+0.392 F R F \\
(R=0.979 \& R 2=0.959) \\
\text { Strength }=1377 \eta+0.0020 \omega n-0.043 F R F \\
(R=0.984 \& R 2=0.968)
\end{array}
$$

\subsection{Detection of Fracture using Traditional Modal Analysis}

The egg excitation was through plastic tip through a frequency range of (0 to $1.6 \mathrm{kHz}$ ). Estimation of transfer function was performed with F.F.T analyzer. The fundamental frequency was estimated from transfer function. Another experiment with a narrow band width of $(800 \mathrm{~Hz})$, centered on the fundamental frequency, was performed to more precisely determine the fundamental frequency.

Transfer function, fundamental frequency and damping estimates were recorded using the halfpower band width at artificial crack. Values incrementally from $(0$ to $3 \mathrm{~cm})$. The results of the study are presented in Fig. $(7 \mathrm{a}, \mathrm{b})$.

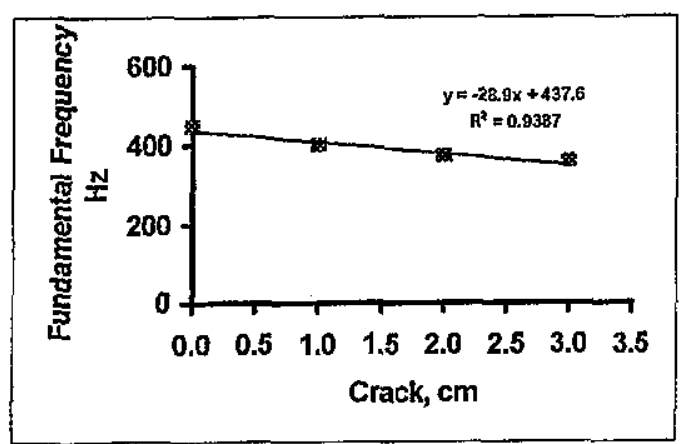

Fig. (7a). Fundamental frequency with variable crack length (position of accelerometer near crack).

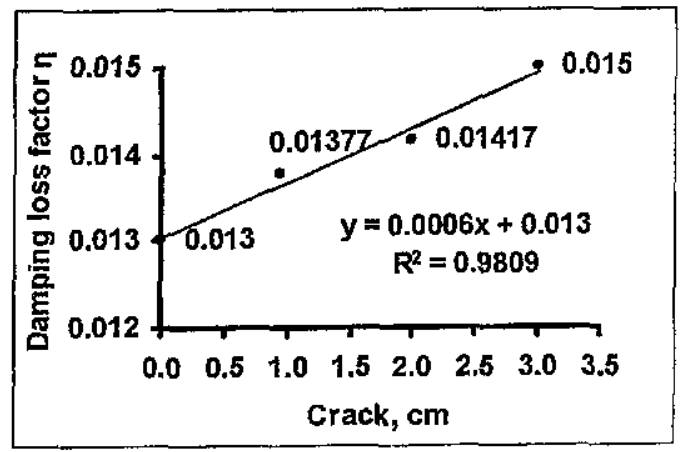

Fig. (7b). Damping loss factor with variable crack length (position of accelerometer near crack)

The Fig. shows that the fundamental frequency slight decreasing for long crack, for small crack not significant at $\omega_{\mathrm{n}}$. The effect of crack on damping coefficient, this no significant at low crack but for long crack there is slight increasing in damping then the low sensitivity of modal parameter $\left(\omega_{n}, \eta\right)$ through the fundamentally can not detect damage therefore transmittance function was constructed. 


\subsection{Detection of Damage Index using}

Transmittance Function.

For the transmittance tests, the response in frequency domain of two sensors is compared with each other through two channel A, B thus the transmittance function was calculated using equation (8) where a darnage index is used to quantify the dynamic properties of structure in damage state composed to healthy state [37] using measured transmittance function across a given frequency range $(0-200 \mathrm{~Hz})$ in terms of scalar value according to equation (8).

$D_{i j}=\frac{\int_{f_{1}}^{f_{2}}\left|T_{i j}{ }^{h}(f)-T_{i j}{ }^{d}(f)\right| d f}{\int_{f_{1}}^{f_{2}}\left|T_{i j}{ }^{h}(f)\right| d f}$

$T_{i j}{ }^{h}$ : is transmittance function of response point $i$,

relative to response $j$ in healthy state and

$T_{i j}{ }^{d}$ : Response the damage state.

A matrix of damage indices are computed for the system whose size is equal to the number of response point measured. This matrix can be interpreted based upon the phenomenon being measured.
Transmittance function estimates were made in frequency range from $(0 \mathrm{~Hz}-1.6 \mathrm{KHz})$, which was divided into a series of sub range with $(200 \mathrm{~Hz})$ band width. The various analysis band widths were investigated so as to determine the best range to detect the fracture of the eggshell. The use of smaller band width allows for a higher frequency resolution than would be possible if the damage estimates were taken over the entire $(0-1.6 \mathrm{KHz})$ range. The frequency band from $(0-200 \mathrm{~Hz})$ was observed to produce the most sensitivity of the damage index of fracture in eggshell. A sample of transmittance function, for this frequency range is presented in Fig. (8a) based upon the instrumentation scheme in Fig. $(3 a, b)$ the healthy state is represented by zero crack and fracture state plotted corresponds to crack $(1,2,3 \mathrm{~cm})$.

The damage index was computed for cracked state as in Fig. (8b) includes a complete state of transmittance function for input frequency $(0-200$ $\mathrm{Hz}),(0-1,6 \mathrm{KHz})$ range, an increasing trend with crack is observed as shown in Fig. (8b) the band width from $(0-200 \mathrm{~Hz})$ was observed to produce the most sensitivity of the damage index to fracture. A sample of this frequency ranges is presented in Fig. (8a).

\begin{tabular}{|c|c|c|c|c|c|c|}
\hline \multicolumn{7}{|c|}{$\begin{array}{l}\text { Table (3). Descriptive Statistics of Vibration Analysis for } \\
\text { Two strain of eggshell. }\end{array}$} \\
\hline Items & \multirow{2}{*}{ Mean } & \multicolumn{2}{|c|}{ Range } & \multirow{2}{*}{ Var. } & \multirow{2}{*}{ S.E. } & \multirow{2}{*}{ c.V.\% } \\
\hline & & Min. & Max. & & & \\
\hline \multicolumn{7}{|c|}{ Ross Strain } \\
\hline Thickness (T, $\mu \mathrm{mm})$ & 41.39 & 33.33 & 45.67 & 20.9 & 1.865 & 11.03 \\
\hline Strength $(\mathrm{P}, \mathrm{N})$ & 29 & 22 & 40 & 52 & 2.94 & 24.87 \\
\hline Natural Frequency $\left(w_{n}\right)$ & 1055 & 210 & 1500 & 238470 & 199.36 & 46.29 \\
\hline Damping Loss Factor $(\eta)$ & 0.012 & 0.006 & 0.016 & 0.002 & 0.0018 & $\overline{36.67}$ \\
\hline Dynamic Stiffiness $\left(k_{\mathrm{sy}}\right)$ & 0.120 & 0.012 & 0.160 & 0.001 & 0.0223 & $\overline{45.58}$ \\
\hline $\begin{array}{l}\text { Frequency Response Function (FRF), } \\
\text { Magnitude }\end{array}$ & 56.67 & 39 & 82 & 328 & 7,392 & 31.95 \\
\hline \multicolumn{7}{|c|}{ Lohmann Selected Leghorn } \\
\hline Thickness $(\mathrm{T}, \mu \mathrm{mm})$ & 38.67 & 31.67 & 42.67 & 16.4 & 1.651 & 10.46 \\
\hline Strength $(P, N)$ & 32 & 23 & 48 & 93.4 & 3.945 & 30.19 \\
\hline Natural Frequency $\left(\omega_{\mathrm{B}}\right) \mathrm{Hz}$ & 872 & 210 & 1600 & 286057 & 218.35 & 61.34 \\
\hline Damping Loss Factor $(\eta) \%$ & 0.0127 & 0.005 & 0.018 & 0.003 & 0.0023 & 44.88 \\
\hline Dynamic Stiffness $\left(k_{\mathrm{dy}}\right) \mathrm{db} / \mathrm{unit}$ & 0.0868 & 0.013 & 0.170 & 0.002 & 0.0315 & 88.82 \\
\hline $\begin{array}{l}\text { Frequency Response Function } \\
\text { Magnitude) db/unit }\end{array}$ & 49.5 & 20 & 90 & 630 & 10.243 & so.69 \\
\hline
\end{tabular}




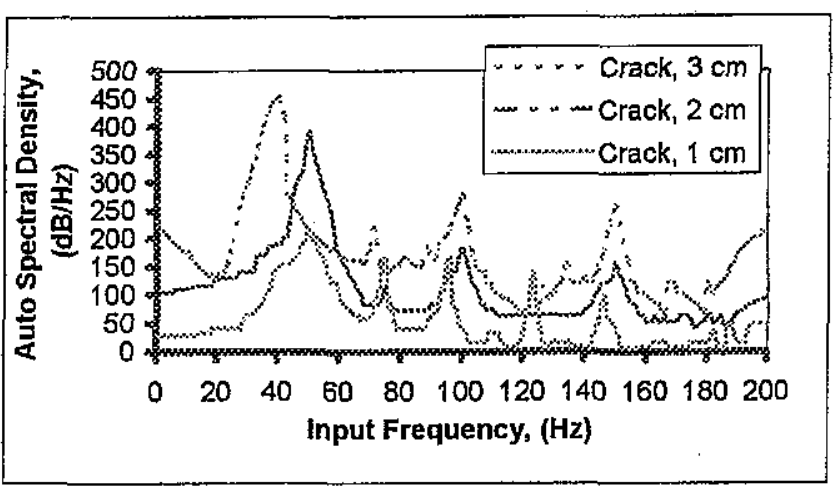

Fig. (8 a) Transmittance Function with accelerometers for variable crake length $(0-200 \mathrm{~Hz})$ range.

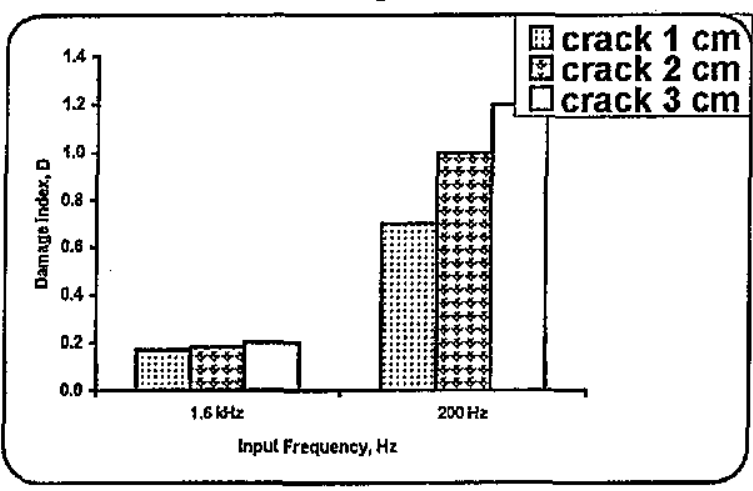

Fig. (8 b). The damage indices of sensor $A$ to $B$ with variable level of crack for different band width.

\subsection{Effect of egg suspension on dynamic signal.}

Fig. (9) shows that the constrains imposed on the egg by suspension methods tended to damped the vibrations at different resonant Frequencies differently. The hinging method imposed the least constraints on the egg, and the power spectrum showed the highest amplitude at the first resonant frequency followed by the second and the third in decreasing order. The power spectrum obtained with resting on the cup was similar to that obtained with hanged, but the amplitude at the first resonant was slightly damped out by the cup. The test results show that there are one extra mode below $50 \mathrm{~Hz}$ are due to the fixed support, are rigid mode and has no effect on elastic natural frequency.

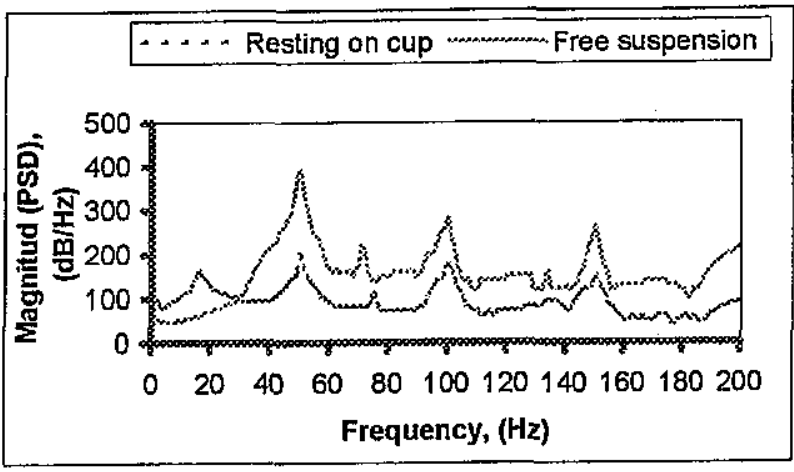

Fig. (9): Effect of egg suspension on dynamic signal

\section{CONCLUSIONS.}

1. The experimental technique described here illustrates the efficiency and robustness of the modified transmittance function to detect damage; it is also shown that, for variable range of frequency it can be used to detect variable damage.

2. Damping parameter can be considered as an efficient tool for detecting the rate of change of growth of crack

3- The correlation between strength measured and modal parameters was highly significant, damping loss factor can distinguish the strength for two types of eggshell.

4. The mode of elasticity of eggshell was obtained from dynamic measurements with formula for complete spherical shell, the technique in this work enable to measure the modulus of elasticity several times.

5.The experimentally obtained modal parameters for two types of egg are in agreement with their structural and macro characteristics, this fact will supports the rationally and reliability of these proposed testing strategy.

6. The data produced by operational modal analysis reveals that this is a capable, powerful experimental technique that can be used to examine the fracture structure within the eggshell, indicate a complex design that has been formed in order to maximize the functional properties. This study has provided valuable information of the eggshell and is useful as structural information to predict fracture, is required in order to be applied to bioinspired design of novel materials. 


\section{APPENDIX}

\section{Nomenclature}

$\mathrm{T}_{\mathrm{ab}} \quad$ Transmittance function between two response points $a$ and $b$

$\mathrm{G}_{\mathrm{bb}} \quad$ Auto spectral density function

$\mathrm{G}_{\mathrm{ab}} \quad$ Cross spectral density function

$B(f, T)$ Fourier transform for signal $B(t)$

$A(f, T)$ Fourier transform for signal $A(t)$

* Indicates to complex conjugate

$\Delta \mathrm{T} \quad$ A period of measurement

$\mathrm{N}_{\mathrm{d}} \quad$ Distinct sub record

$\mathrm{ARM}_{(\mathrm{i})}$ Average value of the reference response (magnitude) for Measurements

MA Modal analysis

TMA Traditional Modal Analysis (Impact test)

ROSS Type of egg for broiler, Lohmann selected Leghorn

Type of egg for Laying

$\eta \quad$ Damping loss factor

$\omega_{\mathrm{n}} \quad$ Natural frequency

$\omega_{\text {ni }} \quad$ Natural frequency of $i$ mode (hertz)

$\lambda \quad$ Non dimensional frequency parameter depending on natural frequency

h Thickness of shell

E Modulus of elasticity

$\mathrm{R} \quad$ Radius of the sphere to the mid surface

$\mu \quad$ Density of the shell egg

$v \quad$ Poisson's ratio

FEA Finite element analysis

SD Standard deviation

ODS Operating deflection shape

$E_{\mathrm{sg}} \quad$ Specific gravity of the egg

$\mathrm{S}_{\mathrm{th}} \quad$ Shell thickness

$E_{\mathrm{g}} \quad$ Egg mass

$\mathrm{S}_{\mathrm{m}} \quad$ Shell mass

$\delta \quad$ Shell deformation

$D_{i j} \quad$ Damage index at point $\mathrm{i}$ relative to point $\mathrm{J}$

Thij Transmittance function of response $i$ relative to response $j$ in health state.

$T_{\mathrm{jjd}} \quad$ Transmittance function of response $i$ to response $\mathrm{j}$ in Damage state

SAS Statistical analysis system

ANOVA Analysis of variance

\section{REFERENCES.}

[1] Elster, R.T. and J.W. Goodrum. 1991. Detection of cracks in eggs using machine vision. Transaction of the ASAE, 34(1): 307-312.

[2] Goodrum, J.W. and R.T. Elster. 1992. Machine vision for crack detection in rotating eggs. Transaction of the ASAE, 35(4): 1323-1328.
[3] Patel, V.C., R.W. McClendon, and J.W. Goodrum. 1994. Crack detection in eggs using computer vision and neural networks. AI Applications, 8(2):21-31.

[4] García-Alegre, M.C., A. Ribeiro, D. Guinea, and G. Cristóbal. 2001. Color index analysis for automatic detection of eggshell defects. URL:http:/www.iv.optica.csic.es/papers/huevos. pdf. [Download: December 18, 2001].

[5] Cho, H.K., W.K. Choi, and J.H. Paek. 2000. Detection of surface cracks in shell eggs by acoustic impulse method. Transaction of the ASAE, 43(6): 1921-1926.

[6] De Ketelaere, B., P. Coucke, and J.D. Baerdemaeker. 2000. Eggshell crack detection based on acoustic resonance frequency analysis. Journal of Agricultural Engineering Research, 76(2): 157-163.

[7] Das, K. and M.D. Evans. 1992. Detecting fertility of hatching eggs using machine vision II: Neural network classifiers. Transaction of the ASAE, 35(6): 2035-2041.

[8] Chen, Y.R., B. Park, R.W. Huffman, and M. Nguyen. 1998. Classification of on-line poultry carcasses with backpropagation neural networks. Journal of Food Process Engineering, 21: 33-48.

[9] Ghazanfari, A., J. Irudayaraj, and A. Kusalik. 1996. Grading pistachio nuts using a neural network approach. Transaction of the ASAE, 39(6): 2319-2324.

[10] Jindal, V.K. and V. Chauhan. 2001. Neural networks approach to modeling food processing operations. In Irudayaraj, J. (ed.), Food Processing Operations Modeling: Design and Analysis, pp. 305-323. New York: Marcel Dekker, Inc.

[11.] De Ketelaere B., D. Moshou, P. Coucke, J. De Baerdemaeker, A hierarchical self-organizing map for classification problems, in: Proceedings WSOM 97: International Workshop on SelfOrganizing Maps, 4-6 June 1997, Helsinki University of Technology, Espoo, Finland, 1997, pp. 86-90.

[12] Coucke P., Assessment of Some Physical Egg Quality Parameters Based on Vibration Analysis, Ph.D. Thesis, Catholic University Leuven, 1998.

[13] Moshou D., B. De Ketelaere, P. Coucke, J. De Baerdemaeker, H. Ramon, A hierarchical selforganizing map for egg breakage classification, in: Third IFAC/ISHS International Workshop on Mathematical and Control Applications in Agriculture and Horticulture, Hannover, Germany, 1997, pp. 125-129.

[14] Brincker, R., L. Zhang and P. Andersen, "Modal identification from ambient responses using frequency domain decomposition, Proc, of 
the 18th international modal analysis conference, San Antonio Texas, February 7-10, 2002.

[15] Hamilton R.M.G., Methods and factors that affect the measurement of eggshell quality, Poultry Science 61 (1982) 2022-2039.

[16] Abdallah A.G., R.H. Harms, O. El-Husseiny, Various methods of measuring shell quality in relation to percentage of cracked eggs, Poultry Science 72 (1993) 2038-2043.

[17] Voisey P.W., J.R. Hunt, Relationship between applied force deformation of egg shells and fracture force, Journal of Agricultural Engineering Research 12 (1) (1967) 1-4.

[18] Coucke P., E. Dewil, E. Decuypere, J. De Baerdemaeker, Measuring the mechanical stiffness of an eggshell using resonant frequency analysis, British Poultry Science 40 (1999) 227232.

[19] Doubling, S.w , Farran C.R., Prime, M.B and Sheviz D.W "A review of damage identification methods that examine change in dynamic properties" shock and vibration Digest (1998) vol.,30.

[20] Doubling SW, Farrar CR, Prime MB, Shevitz DW. Damage identification and Health monitoring of structural and mechanical systems form changes in their Vibration characteristics: a literature survey, Report No. LA-12767-MS, Los Alamos, NM:Los Alamos national Laboratory, 1996.

[21] Farrar CR, Doebling SW. An Overview of modal-based damage identification methods. Proceeding of DAMAS conference, Sheffield, UK.1997.

[22] Zouy, Tong L,Steven GP. Vibration-based model-dependent damage (delamination) identification and health monitoring for composite structures-a review. Journal of sound and vibration 2000; 230(2):357-78.

[23] Todd MD, Nicholas JM, Pecora LM, Virgin LN. Vibration-based damage assessment utilization state space geometry changes: local attractor variance ratio. Smart Materials and Structures 2001; 10:1000-8.

[24] Yan YJ, Yam LH. Online detection of crack damage in composite plates using embedded piezoelectric actuators/sensors and wavelet analysis .Composite structures 2002; 58:29-38.

[25] Zubaydi A, Haddara MR, Swamidas ASJ. Damage identification in a ship's structure using neural networks. Ocean Engineering 2002; 29:1187-200.

[26] Salawu OS. Detection of structural damage through changes in frequency: a review. Engineering Structures 1997;19 (9):718 -23.
[27] Ganguli R. A fuzzy logic system for ground based structural health monitoring of a helicopter rotor using modal data. Journal of intelligent Material System and Structures 2001; 12:397407.

[28] Kuo EY, Jayasuriya AMM. A high mileage vehicle body joint degradation estimation method. International Journal of Materials and Product Technology 2002; 17(5/6):400-10.

[29] Ghoshal A, Sundaresan MJ, Schulz MJ, Pai PF. Structural health monitoring techniques for wind turbine blades. Journal of Wind Engineering and Industrial Aerodynamics 2000; 85:309-24

[30] Schulz MJ, Pai PF, Inman DJ. Health monitoring and active control of composite structures using piezoceramic patches. Composites: Part B 1999; 30:713 -25.

[31] Brian Schwarz \& Mark Richardson (Measuring operating Deflection shapes under nonstationary conditions. 18th International Conference of Modal Analysis. February 7-10 IMAG 2000.

[32] Damir A. N., A.El khatib, G. Nasser (Prediction of fatigue life using modal analysis PEDAC (2004).

[33] Blevins, Robert D (Formulas for natural frequency and mode shape.) copyright 1979 by Litton Enducatimal publishing, Inc

[34] Amer Essa, A.H. (1998). The engineering factors affecting handling and loss reduction of egg production. Ph.D Thesis, University of Minoufiya, Shibin El-Kom, Egypt.

[35] Mohanty P., D.J.Rixen "Operational modal analysis in presence of harmonic excitation ", Journal of sound and vibration 270 (2004) 93109.

[36] Mark Richardson and Ron Potter (Identification of Modal properties of Elastic Structure from Measured Transfer function Data. 20th International Instrumentation Symposium 1974 ISAASI 74250 (239-246).

[37] Vicent Caccese, Richard Mewer and Senthils. Vel (Detection of bolt loss in hybrid composite/metal bolted connection. Journal of Engineering structure 26 (2004) 895-906.

[38] Seide, P., Small Elastic Deformation of thin shells Noordholf International publishing, Leyden, the Netherlands, 1975, pp. 615-620.

[39] Wang DH, Huang SL. Health monitoring and diagnosis for flexible structures with PVDF piezoelectric film. senor array. Journal of Intelligent Material System and structures 2000; 11:482-91.

[40] SAS (2000) SAS- stat user's Guide version 6 5th edition, SAS institute inc., Cary, NC, USA. 